\title{
APPEAL FOR GUIDANCE ON RULES FOR THE 7th WMCC
}

\section{The Board of ICCA}

During the course of the recent 6th WMCC the ICCA Board formed an ad hoc committee to review all aspects of computer-chess competitions, but especially the microcomputer events, to ensure that both vested interests are protected and yet that hardware/software innovations can be encouraged. There is some urgency in this matter, since a proposal for the 7th WMCC has been received from a group in Italy. You are invited, therefore, to send your thoughts on this matter to David Levy immediately. The issues are: Should the event have separate hardware and software categories? Should the hardware category be set aside for entrants from bone fide manufacturers of computer-chess machines? Should there be hardware restrictions on the entrants?

Some simple limits to be considered are:

\begin{tabular}{|l|l|l|l|}
\hline number of processors & 1 & 4 & unlimited \\
bitslice technology & yes & no & \\
gate-array technology & yes & no & \\
memory & $128 \mathrm{~Kb}$ & $1 \mathrm{Mb}$ & unlimited \\
power consumption & $100 \mathrm{~W}$ & $250 \mathrm{~W}$ & unlimited \\
weight & $10 \mathrm{Kg}$ & $25 \mathrm{Kg}$ & unlimited \\
bits/word & 8 & 16 & unlimited \\
hardware assists (accelerator cards) & yes & no & \\
special-purpose custom-design chips & yes & no & \\
\hline
\end{tabular}

Should the ICCA sanction two parallel events: (a) hardware manufacturers, (b) software developers, followed by a play-off for the championship? The idea here is to provide a forum for information exchange between hardware/software vendors.

What kind of titles should be awarded, and should the ICCA authorize specific identifying statements that the manufacturers may attach to their products?

Are there other issues of concern and interest that should be considered?

The committee reviewing these issues is: David Levy (Intelligent Chess Software), Chairman; Richard Lang (Hegener \& Glaser); Tony Marsland (University of Alberta); Sid Samole (Fidelity Electronics); Tony Scherzer (Sys-10 Inc.). All responses should be directed to David Levy, as quick as possible, address see inside-cover page.

\section{THE FIFTH CONFERENCE ON ADVANCES IN COMPUTER CHESS}

Noordwijkerhout, April 27-28, 1987

The Editors are pleased to recall to readers that the Fifth Conference on Advances in Computer Chess will take place on

\author{
April 27 and 28, 1987 \\ at Congres Center De Leeuwenhorst \\ Noordwijkerhout (near Leiden) \\ The Netherlands
}

as communicated in this Journal in its June issue (pp. 116-117). Details published there are still in force, except that late submissions of papers will be acceptable if reaching Don Beal or J.J. van Oosterwijk Bruyn within two weeks of your receiving this issue.

The same extension in time applies to applications for participation in the conference, except that advance-booking discounts are no longer applicable. 